\title{
Pneumomediastinum complicating pulmonary tuberculosis with diabetic ketoacidosis
}

\author{
Bruno Mendonça Protásio ${ }^{a}$, Jamile Rosário Kalila , João Gabriel Rosa Ramosa ${ }^{\text {, Eberth Alves }}$ \\ Machado Neto ${ }^{a}$, Alex Teixeira Guabirua ${ }^{a}$ Vilma Takayasu ${ }^{b}$
}

Protásio BM, Kalil JR, Ramos JGR, Machado Neto EA, Guabiru AT, Takayasu V. Pneumomediastinum complicating pulmonary tuberculosis with diabetic ketoacidosis. Autopsy Case Rep [Internet]. 2011;1(2):57-62.

\section{ABSTRACT}

\begin{abstract}
We report a case of a 43-year-old man, previously healthy, with a three-month history of weight loss, dyspnea, cough, hemoptysis and chest pain, followed by polyuria and polydipsia during the last weeks. Clinical investigation disclosed diabetic ketoacidosis, pulmonary tuberculosis and pneumomediastinum. The patient's outcome was favorable after clinical treatment and the pneumomediastinum resolved spontaneously without specific intervention.
\end{abstract}

Keywords: Tuberculosis; Pneumomediastinum, diagonostic; Mediastinal emphysema; Diabetic ketoacidosis.

\section{INTRODUCTION}

Pneumodiastinum has been described as a rare complication of diabetic ketoacidosis ${ }^{1}$ and pulmonary tuberculosis ${ }^{2-4}$. However it has not been reported concomitantly with both diseases. Pulmonary tuberculosis is an infrequent cause of diabetic ketoacidosis. ${ }^{5}$ We here report a case of pneumomediastinum in a patient with previously undiagnosed diabetes mellitus that presented with diabetic ketoacidosis and pulmonary tuberculosis.

\section{CASE REPORT}

A previously healthy 43-year-old man was admitted to the emergency room of the Hospital Universitário da Universidade de São Paulo (HU-USP) with a three-month history of weight loss, dyspnea, cough, chest pain and hemoptysis. The patient also reported polyuria and polydipsia in the previous weeks. At physical examination, patient was dehydrated, his body mass index was $16.4 \mathrm{~kg} / \mathrm{m}^{2}$, heart rate was 143 beats/min, blood pressure $150 \times 100$ $\mathrm{mmHg}$ and pulse oximetry $97 \%$. Initial investigation is shown in Table 1.

\footnotetext{
a Hospital das Clínicas da Faculdade de Medicina - Universidade de São Paulo, São Paulo/SP, Brazil.

b Divisão de Clínica Médica do Hospital Universitário - Universidade de São Paulo, São Paulo/SP, Brazil.
} 
Tabela 1 - Laboratory examinations

\begin{tabular}{llllll}
\hline Hemoglobin & $\mathrm{g} / \mathrm{dl}$ & 16.1 & Base excess & & $-22,1$ \\
Hematocrit & $\%$ & 51 & BUN & $\mathrm{mg} / \mathrm{dl}$ & 39 \\
Leuckocytes & $/ \mathrm{mm} 3$ & 22100 & Creatinin & $\mathrm{mg} / \mathrm{dl}$ & 1.4 \\
Glucose & $\mathrm{mg} / \mathrm{dl}$ & 695 & Sodium & $\mathrm{mEq} / \mathrm{l}$ & 108 \\
Glicated hemoglobin & $\%$ & 13.9 & corrected Sodium * & $\mathrm{mEq} / \mathrm{l}$ & 118 \\
$\mathrm{pH}$ (venous) & & 7,05 & Potassium & $\mathrm{mEq} / \mathrm{l}$ & 6.5 \\
Bicarbonate (venous) & $\mathrm{mEq} / \mathrm{l}$ & 8.0 & & & \\
\hline
\end{tabular}

*Sodium corrected for glucose level mEq/l

Urinalysis revealed 4500 leucocytes $/ \mathrm{ml}$, 19500 red blood cells/ml and ketonuria, "1+/4. tion in the right lower lobe, associated with evidence of pneumomediastinum. (Figure 1).

Chest radiography demonstrated a cavita-

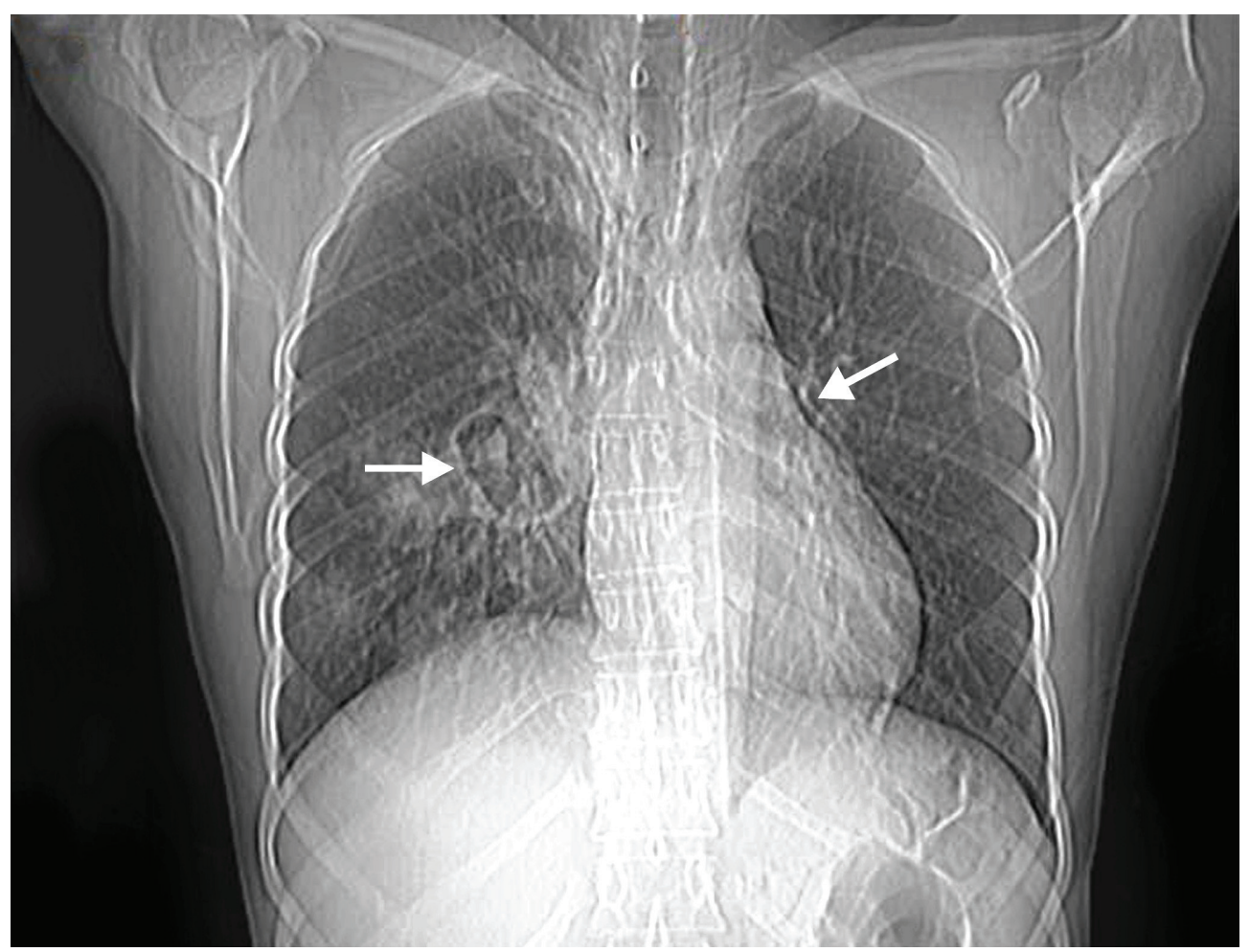

Figure 1 - Chest radiograph at admission showing pneumomediastinum along left cardiac border (left arrow) and a pulmonary cavitation in the right lung (right arrow)

Computed tomography of the thorax was performed (Figures 2, 3, 4 and 5), which confirmed the presence of pneumomediastinum associated with soft tissue emphysema in the neck. The chest CT also showed the presence of a cavitation in the apex of the lower lobe of the right lung, measuring $4.7 \times 3.0 \mathrm{~cm}$, multiple ill-defined opacifications with air-bronchograms, small centrilobular nodules with tree-in-bud appearance, areas of ground glass attenuation in right lower lobe and hilar adenopathy. 


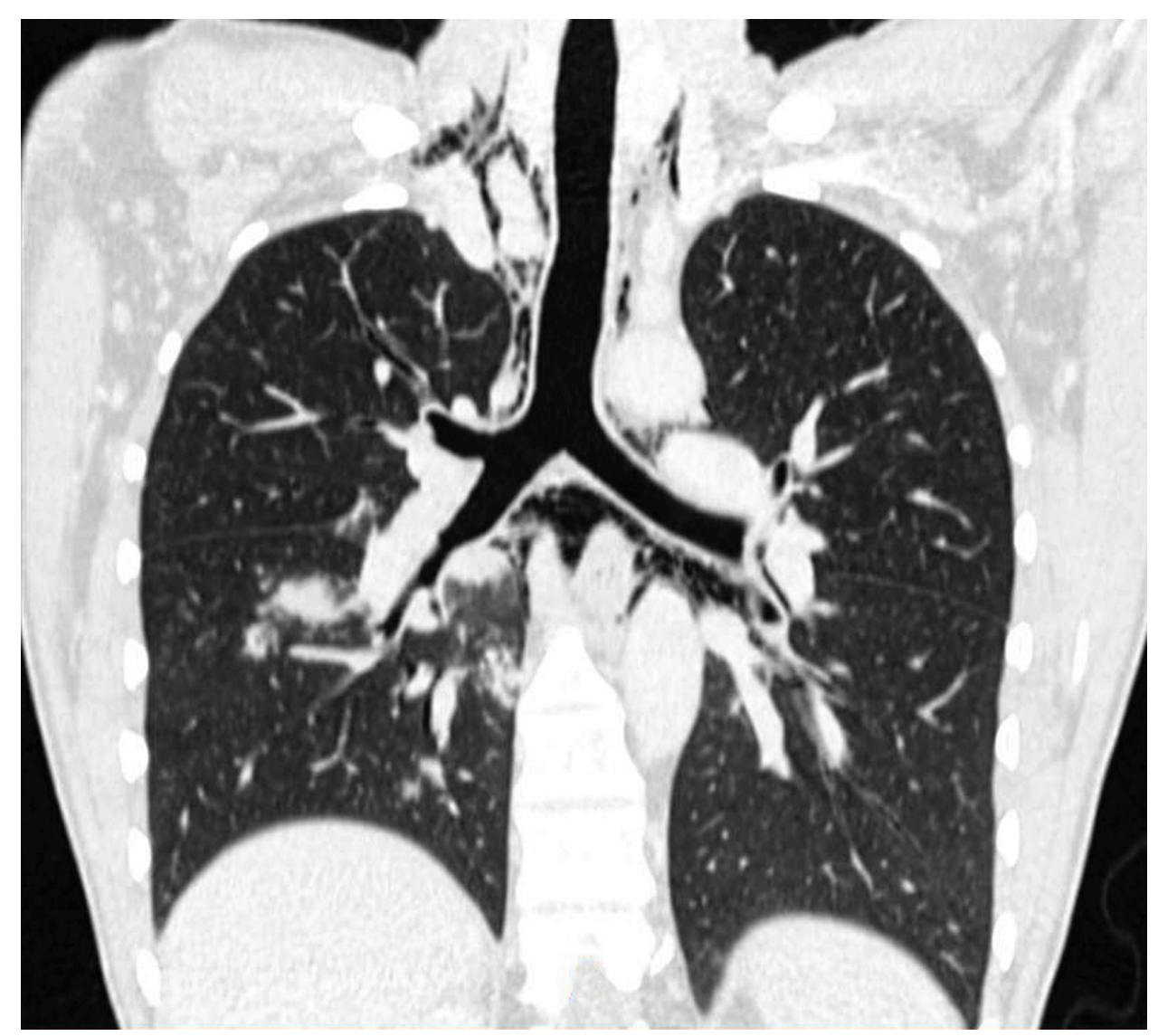

Figure 2 - Coronal slice of Chest CT showing presence of air in the subcarinal space and in the neck

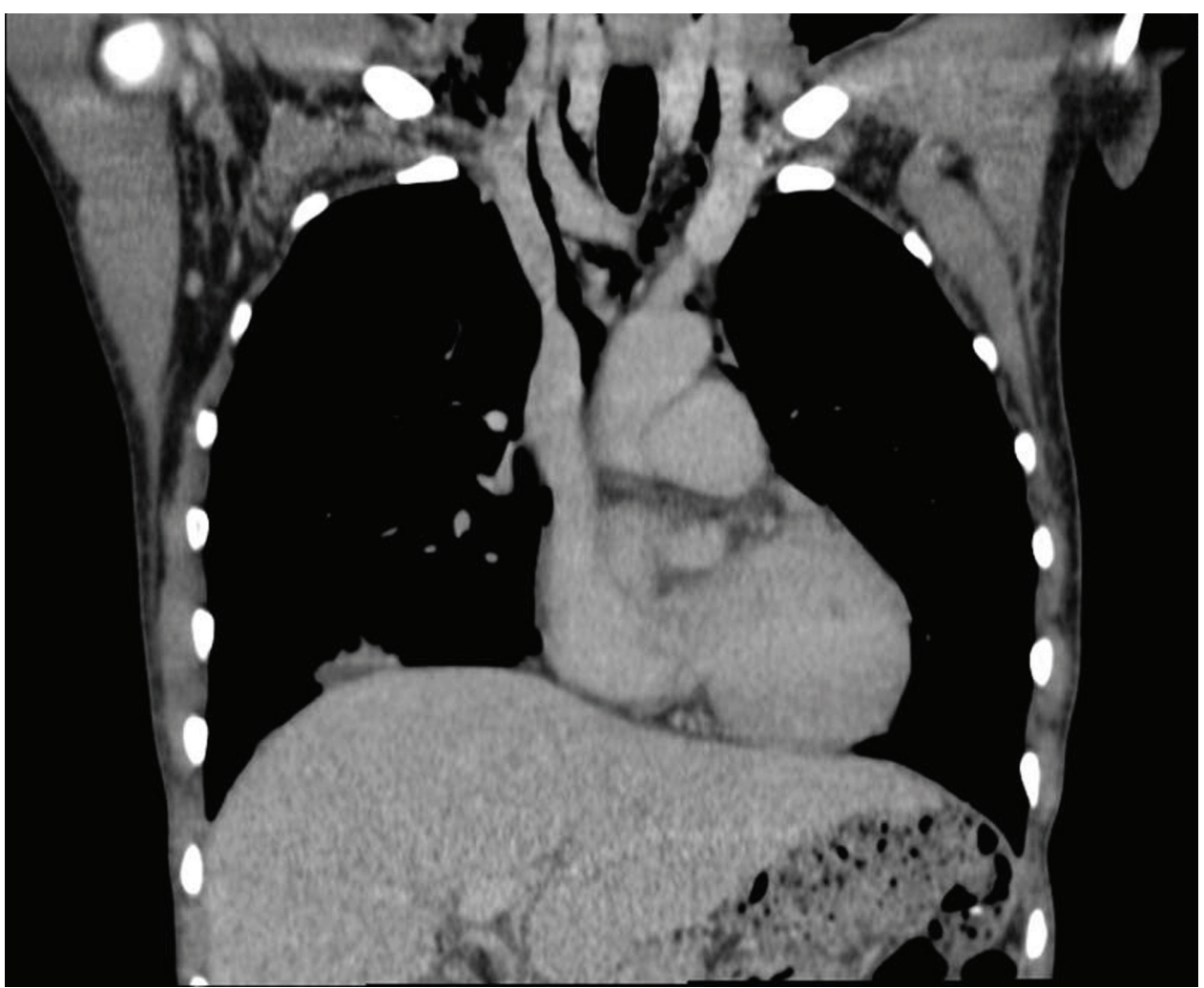

Figure 3 - Coronal slice of Chest CT demonstrating the presence of pneumomediastinum and air within the soft tissue of the neck 


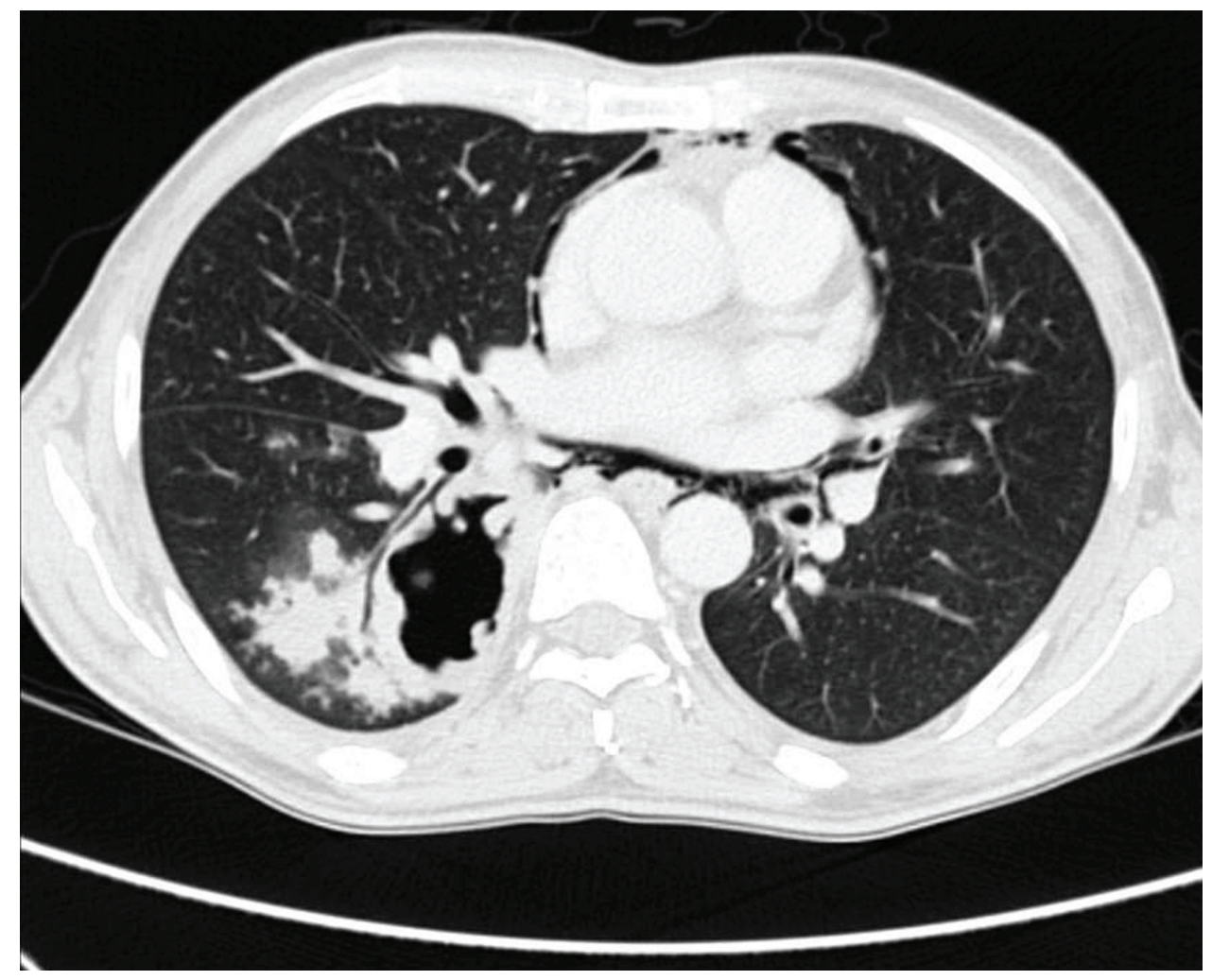

Figure 4 - Chest CT showing multiple ill-defined opacifications with air-bronchograms and cavitation in right lower lobe

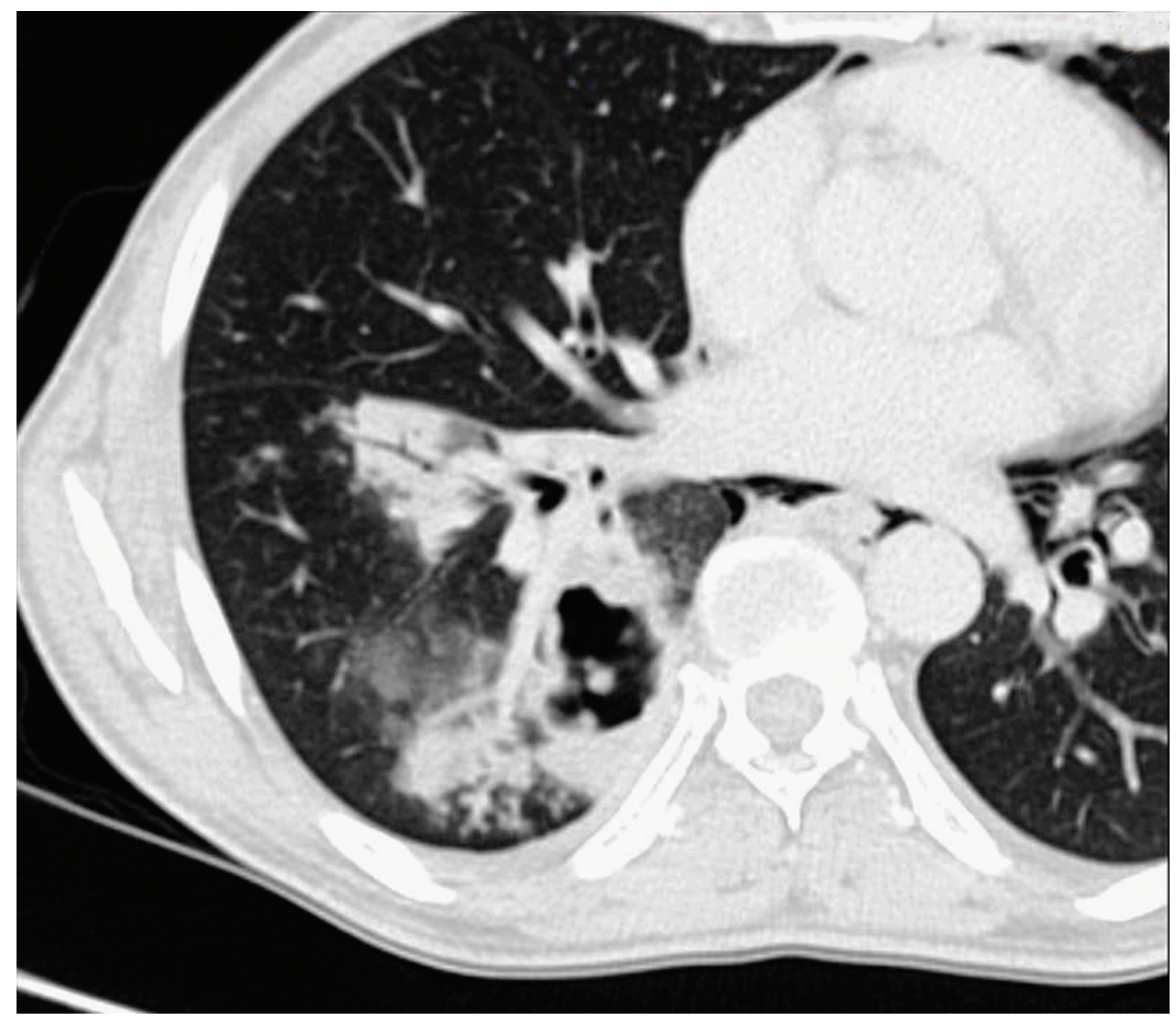

Figure 5 - Chest CT showing small centrilobular nodules with tree-in-bud appearance, areas of ground glass attenuation and cavitation in right lower lobe 
Diagnosis of decompensated diabetes mellitus presenting as diabetic ketoacidosis (DKA) due to pulmonary tuberculosis was made and the patient was treated for DKA with aggressive hydration, insulin therapy. and correction of the electrolyte disturbances. Acid-fast bacilli were demonstrated in the sputum $(2+14+)$ in two consecutive samples and the culture was positive for Micobacterium tuberculosis. Anti-HIV (ELISA) was negative. Standard brazilian tuberculosis treatment (rifampicin $600 \mathrm{mg}$, isoniazid $300 \mathrm{mg}$, pyrazinamide $1600 \mathrm{mg}$ and ethambutol $1100 \mathrm{mg}$, daily) was prescribed followed by clinical improvement. Pneumomediastinum was treated conservatively. Folow-up chest $\mathrm{x}$-ray, performed four days later, showed spontaneous resolution of the pneumomediastinum. The patient demonstrated a rapid response to the treatment, with clinical improvement and complete resolution of the ketoacidosis and was discharged afteer twelfth day of hospitalization. Patient was followed on an outpatient basis, in use of anti-tuberculosis drugs and daily doses of insulin.

\section{DISCUSSION}

This is, to our knowledge, the first report of a patient with pneumomediastinum complicating the presentation of pulmonary tuberculosis associated with diabetes ketoacidosis. Despite the known association between diabetes mellitus and tuberculo$\mathrm{sis}^{6}$, pulmonary tuberculosis does not seem to be a frequent cause of first presentation of diabetes as diabetic ketoacidosis. ${ }^{5}$

About 60 cases of pneumomediastinum associated to diabetic ketoacidosis were reported until 2007. ${ }^{1}$ The number of cases of pneumomediastinum and pulmonary tuberculosis is even smaller. ${ }^{2-4,7}$ We could not find any report showing the concomitance of both etiologies and pneumomediastinum until now.

Pneumomediastinum, also known as mediastinal emphysema, represents extra luminal gas in the mediastinum and usually occurs as a result of alveolar rupture, most commonly due to increased alveolar pressure secondary to airway obstruction, mechanical ventilation, blunt trauma, coughing, emesis, or Valsalva maneuver. ${ }^{8}$ Less common and more serious causes of pneumomediastinum include bronchus or esophagus rupture. ${ }^{8}$ It is believed that lung infection caused by Mycobacterium tuberculosis could lead to alveolar rupture with subsequent passage of gas into the mediastinum, which could be aggravated by elevated alveolar pressure due to Valsava maneuver associated with intense coughing. 7,8 The pathophysiology of pneumomediastinum associated with diabetic ketoacidosis remains controversial ${ }^{1}$, but it seems that increased alveolar pressure associated with acidotic (Kussmaul) respiration and vomiting could cause alveolar rupture, leading to subsequent air leakage to the mediastinum. ${ }^{1,8}$

Pneumomediastinum seems to be rarely associated with active tuberculosis ${ }^{7}$ or diabetes ketoacidosis. ${ }^{9}$ Cases reportes of tuberculosis and pneumomediastinum differ in clinical presentation, as some of them are associated with miliary tuberculosis $^{3}$, others with sequelae of previously treated tuberculosis ${ }^{4}$ and others with active pulmonary tuberculosis. ${ }^{2}$ Although one case was complicated with tension pneumomediastinum, necessitating surgical approach ${ }^{7}$, most reported cases improved without any interference. ${ }^{4}$ Unlike our report, most cases of diabetic ketoacidosis associated with pneumomediastinum involved younger patients [mean age $(S D)=20(10.3)$ years] $^{9}$, but similarly to this case, a great proportion of them had no previous diagnosis of diabetes and all of them had complete spontaneous recovery. ${ }^{1}$ This benign natural course and the low yield of diagnostic testing has also been shown in other causes of spontaneous pneumomediastinum. ${ }^{10}$

In this case, one could not ascertain the primary cause of the pneumomediastinum, since both pulmonary tuberculosis and diabetic ketoacidosis could have concurred to this complication. As the incidence of diabetes mellitus is increasing in countries with a high burden of tuberculosis, it could be foreseen that complications involving these two conditions could become each day more common, so that clinicians should maintain a high degree of suspicion for this diagnosis.

\section{CONCLUSION}

Pneumomediastinum is a rare complication of pulmonary tuberculosis and diabetic ketoacidosis. The clinical presentation of mediastinal emphysema associated with these two diseases may be variable and therefore clinicians should be alert to this diagnosis. Although pneumomediastinum may be associated with important pathologies and lifethreatening complications, most cases follow a benign course and should be treated conservatively. 


\section{REFERENCES}

1. Pauw RG, van der Werf TS, van Dullemen HM, Dullaart RP. Mediastinal emphysema complicating diabetic ketoacidosis: plea for conservative diagnostic approach. Neth J Med. 2007;65(10):368-71.

2. Gupta A, Jain N, Singh C, Sharma DK. Pneumomediastinum in association with pulmonary tuberculosis. J Assoc Physicians Índia. 1996;44(11):821-3.

3. Das M, Chandra U, Natchu M, Lodha R, Kabra SK. Pneumomediastinum and subcutaneous emphysema in acute miliary tuberculosis. Indian J Pediatr. 2004;71(6):553-4.

4. Qureshi SA. Spontaneous pneumonediastinum associated with pulmonary cavitation. Postgrad Med J. 1980;56(651):48-9.

5. Otieno CF, Kayima JK, Omonge EO, Oyoo GO. Diabetic ketoacidosis: risk factors, mechanisms and management strategies in sub-Saharan Africa: a review. East Afr Med J. 2005;82(12 Suppl):S197-203.

\section{Conflict of interest: None}

Submitted on: $7^{\text {th }}$ April 2011

Accept on: 19th May 2011

Correspondence: Bruno Mendonça Protásio

Rua Amazonas, 159, ap. 301, Pituba, Salvador, Bahia, Brazil.

ZIP code: $41830-380$

E-mail: bruno_protasio@yahoo.com.br
6. Dooley KE, Chaisson RE. Tuberculosis and diabetes mellitus: convergence of two epidemics. Lancet Infect Dis. 2009;9(12):737-46.

7. Class RN, Pacheco MR. Spontaneous tension pneumomediastinum complicating pulmonary tuberculosis. Dis Chest. 1965;48(6):621-7.

8. Bejvan SM, Godwin JD. Pneumomediastinum: old signs and new signs. AJR Am J Roentgenol. 1996;166(5):1041-8.

9. Pooyan P, Puruckherr M, Summers JA, Byrd RP, Jr., Roy TM. Pneumomediastinum, pneumopericardium, and epidural pneumatosis in DKA. J Diabet Complicat. 2004;18(4):242-7.

10. Iyer VN, Joshi AY, Ryu JH. Spontaneous pneumomediastinum: analysis of 62 consecutive adult patients. Mayo Clin Proc. 2009;84(5):417-21. 